\title{
Reproductive biology of Pittosporum dasycaulon Miq., (Family Pittosporaceae) a rare medicinal tree endemic to Western Ghats
}

\author{
Krishna Kumar Gopalakrishnan ${ }^{1}$ and Thuruthiyil Dennis Thomas ${ }^{1,2^{*}}$
}

\begin{abstract}
Background: For successful cultivation and conservation of plants a detailed knowledge of their reproductive biology is required. The reproductive features of trees are important to determine the diversity patterns and community structure of tropical forests. The present study on reproductive biology of Pittosporum dasycaulon, a rare medicinal tree, was conducted in the shola forests of Vaghamon hills, one of the foot hills of Southern Western Ghats of India from 2008-2011.

Results: The plant flowers profusely during February to April. Inflorescence is a raceme and the total number of flowers per inflorescence varies from 96-217. The flowers are comparatively small, hermaphrodite, short pedicellate, complete, zygomorphic, pentamerous, polypetalous, hypogynous and light cream in colour with an average length of $1.14 \mathrm{~cm}$. Anthesis started at $08.30 \mathrm{~h}$ and the flowers were completely opened at approximately $09.30 \mathrm{~h}$ followed by anther deshiscence at 10.00-11.30 h. The pollen grains were trizonocolpate with $45 \pm 5.6 \mu \mathrm{m}$ in size. Acetocarmine staining showed $66 \pm 6 \%$ fertile pollen at the time of anther dehiscence. The number of pollen grains in an anther is $5246 \pm 845$ and per flower is $26230 \pm 1021$. The stigma is wet, non-papillate, capitate and contains a thin film of exudates under the light microscope. The superior ovary is densely covered with papillate hairs and containing 3-8 ovules. The important floral visitors include bees and butterflies. The plant is self-incompatible and an out crosser. Fruit set under open-pollination was poor (24\%) with $58.3 \%$ fruits having seeds inside. There was no fruit set in manually self pollinated flowers while over $57 \%$ of the cross pollinated flowers set fruits.
\end{abstract}

Conclusions: Our study presents a detailed account on reproductive biology of this medicinal tree which may help in the conservation and genetic improvement of this particular taxa.

Keywords: Floral biology; Medicinal tree; Phenology; Pittosporum dasycaulon; Pollen morphology; Reproductive biology

\section{Background}

Reproduction is the life process which ensures the perpetuation of life and genetic diversity is mainly generated through recombination processes in sexual reproduction, which is, hence, a process of fundamental importance for population and species biology (Maynard 1978). For successful cultivation and conservation of plants a detailed knowledge of their reproductive biology is required (Moza and Bhatnagar 2007). Reproductive biology mainly focuses

\footnotetext{
*Correspondence: den_thuruthiyil@yahoo.com

'Postgraduate and Research Department of Botany, St. Thomas College, Palai, Arunapuram (P.O.) PIN 686574, Kottayam (Dt.), Kerala, India

${ }^{2}$ Department of Pharmaceutical Biology and Botany, Medical University in Wroclaw, Al. Jana Kochanowskiego 10, 51-601 Wroclaw, Poland
}

on flowering phenology, floral biology, pollen-pollinator interaction, breeding systems and gene flow through pollen and seeds. The task of plant phenology is to observe and record the periodically recurring growth stages and to study the regularities and dependency of the yearly cycles of development on environmental conditions. In plants phenological events such as bud-burst, leafexpansion, leaf-abscission, flowering, fertilisation, seed set, fruiting, seed dispersal and seed germination all take place in due season. Plant breeding systems extent from full self compatibility to full self incompatibility. Self incompatibility reduces the risk of inbreeding depression by limiting the number of compatible mating pairs, while self compatibility eliminates mate limitation by allowing each

\section{Springer}


individual to self-fertilize. In some plants the fruit set in open pollinated flowers will be very low. This phenomenon is usually observed in hermaphroditic plants (Sutherland, 1986) which exhibit self-incompatibility. Low fruit set in nature may be largely due to a high incidence of self-pollination and a high level of selfincompatibility, but several other causes, such as resource limitation and position of fruit within inflorescences, may also be involved (Bawa and Webb, 1984).

Of the various genus of the family Pittosporaceae, Pittosporum alone is found in India. About 300 species of Pittosporum is reported out of which only eleven are observed in India. Most of the species are useful in traditional Chinese medicine for their sedative and cough relieving effects. Several active phytochemical compounds such as triterpenoid saponins, carotenoids, and essential oils were isolated from Pittosporum (Feng et al. 2010; Chou et al. 2008; Maoka et al. 2008; Seo et al. 2002). The antileukemia properties of Pittosporum had been reported recently by Cragg et al. (2006). The biological properties of Pittosporum has been mainly attributed to the presence of a number of volatile mono and sesquiterpenes in leaves (Chou et al. 2008).

Due to its high medicinal value, the plants are harvested in an excessive manner and thus $P$. dasycaulon needs conservation. There is only very scanty information on reproductive biology of the genus Pittosporum. However, some preliminary reports regarding the reproductive biology of some members of Pittosporaceae has been reported. Dioecy, self-compatibility and vegetative reproduction has been investigated in Hymenosporum flavum (Adam and Williams 2001). Reproductive biology, dispersal and population structure of Pittosporum Undulatum has been studied by Mullett (1996). An adequate understanding of the reproductive strategies of this plant requires detailed studies of their floral biology, reproductive phenology, pollination, and breeding systems. To our knowledge there is no published account on any aspects of reproductive biology or any related areas of this plant. Therefore, the present study provides a detailed account of reproductive biology i.e. phenology, floral biology, floral visitors and breeding system of $P$. dasycaulon.

\section{Methods}

\section{Study species}

Pittosporum dasycaulon (Family-Pittosporaceae) is a rare medicinal evergreen tree growing up to $12 \mathrm{~m}$ height and endemic to Western Ghats. Rare species have very narrow geographical distribution and highly specific habitat requirements and are restricted to small populations only (Primack 1993). P. dasycaulon occupied very limited in number in Western Ghats. Bark is thin, brown and the young branchlets are terete, pubescent and lenticellate. Leaves are simple, alternate, elliptic, subcoriaceous, glabrous and usually crowded at the apex. The leaf base is cuneate and the apex is acute. The population of plant is very limited in each locality and is now in the threatened category. Plant shows high medicinal properties. Stem bark and root bark are bitter and aromatic. It is an expectorant and possesses febrifuge and narcotic properties and is used to cure chronic bronchitis, leprosy, skin diseases and as an antidote for snake poisoning (Udayan et al. 2007; Yesohdharan and Sujana 2007). Recently the antiinflammatory effect of a related species $P$. tetraspermum was confirmed in carrageenan induced oedema in albino rats (Rosakutty et al. 2010). When freshly cut, the bark emits a ginger like smell.

\section{Study site}

The study was carried out for over three years on 4 natural populations comprising 12 plants growing in the grass land and shola forests of Vaghamon hills, Kottayam district, Kerala, India. In fact only those plants were available in the locality and no other trees of the same species were available for study. The approximate age of the marked trees varied from 10-26 years. The approximate height of the trees ranged from 5-12 meters.

\section{Phenology}

Phenological observations were recorded monthly with respect to leaf fall (if any), leaf production, flowering (Including floral bud formation), and fruiting (Period between fruit formation until seed dispersal) on the selected plant in the studying area. The intensities of these phenological events were estimated using the semiquantitative scale of Fournier (Fournier 1974) and identification of the morphological patterns was made according to the classification proposed by Newstrom (Newstrom et al. 1994).

\section{Floral biology}

Flowers of $P$. dasycaulon on the day of anthesis were collected for floral biological studies. Type of inflorescence and the average number of flowers/inflorescence were registered. Length of sepals, petals, stamens and gynoecium were measured. Number of stamens, their arrangement, and time of anther dehiscence were also registered. The nature of stigma, style and the position of ovaries were identified by using a dissection microscope. Number of locules and the number of ovules per locules were registered by taking the free hand sections of ovary. Number of pollen grains per flower and number of ovules per ovary were measured by various methods given by Kearns and Inouye (Kearns and Inouye 1993). Pollen size was measured with an ocular micrometer under light microscope following the procedure of McKone and Webb (McKone and Webb 1988). Pollen morphology was determined by acetolysis (Shivanna and Rangaswamy 
1993). In acetolysis the pollen grains were treated with acetic anhydride and sulfuric acid to dissolve the cellulistic materials present on the surface of the pollen grains and provide better visibility for studying pollen sculpering. Photographs were taken by using a photomicroscope (Labomed, India) attached to a camera (Nikon D70).

\section{Pollen/ovule $(\mathrm{P} / \mathrm{O})$ ratio}

Pollen ovule $(\mathrm{P} / \mathrm{O})$ ratio was verified in pre-anthesis buds by dividing the number of pollen grains by the number of ovules/flower (Cruden 1977). The number of ovules in the ovaries were counted with the help of a dissecting microscope (Nikon). Buds examined for $\mathrm{P} / \mathrm{O}$ ratio were near anthesis i.e. pollen was mature but the anther has not dehisced. The number of buds collected from each specimen varied from 12-20.

\section{Reproductive biology}

Pollen viability tests were conducted by using pollen grains from 25 newly opened bagged flowers. In vitro hanging drop culture method (Brewbaker and Kwack 1963) was used to check the pollen viability. The composition of the Brewbaker and Kwack's medium includes boric acid (100 mg/l), calcium nitrate (300 mg/l), Magnesium sulfate $(200 \mathrm{mg} / \mathrm{l})$, potassium nitrate $(100 \mathrm{mg} / \mathrm{l})$ and sucrose (10\%). The hanging drop method consisted of suspending the pollen grains in a drop of nutrient medium on a coverglass hanging over a shallow depression. The hanging drop culture was sealed with petroleum jelley to prevent evaporation of the culture medium. Time taken for pollen tube germination, and the average length of pollen tubes were measured. Pollen load on stigmatic surface were checked by treating the pistil in $8 \mathrm{~N} \mathrm{NaOH}$. Presence or absence of self incompatibility was also verified by pollen load on stigmatic surface and pollen tube germination on stigmatic surface. Fruit set and seed set were observed every week after pollination.

\section{Breeding systems}

The breeding system of $P$. dasycaulon was conducted by controlled pollination done in flowers that were previously enclosed with paper bags still in the bud preanthesis phase to avoid any kind of natural pollination. Various types of experiments including self-pollination and cross pollinations were carried out (Radford et al. 1974). For controlled pollination, emasculation was carried out as follows. Flower buds were selected about 1-2 days before anthesis, opened carefully and excised all anthers with a forceps, bagged and carefully labelled. On the day of anthesis, the controlled pollinations were carried out. For self-pollination experiments bagged flowers without emasculation were manually pollinated with the same pollen. For cross pollination, emasculated flowers were pollinated with pollen from various other plants. For natural pollination experiments, undisturbed naturally growing flowers were used. The bags were removed from the flowers only after the anthesis and the fruit development was monitored every week. In addition to above treatments, the flowers were also marked to evaluate the percentage of fruit set under natural conditions. We also calculated the reproductive efficacy (the ratio between the percentage of fruits formed by natural pollination and the percentage of fruits formed by hand cross pollination; Bullock 1985). In order to observe pollen tube growth, flowers were hand cross pollinated and the pistils were fixed in FAA (Formaline : acetic acid : alcohol; 5:5:90) at intervals of $8,16,24,48$, and $72 \mathrm{~h}$ after pollinations, studied for pollen tube growth.

\section{Floral visitors}

During the flowering period detailed studies on floral visitors were done. All the plants were observed in the field for more than 20 hours each during the field trips. Floral visitors and their behaviour were recorded from 09:30 AM to 15:00 PM. Type of floral visitors, purpose of visiting, interaction with flowers (which includes attempt to visit flower i.e. flies close without touching the flower, direct contact and effect pollination) were

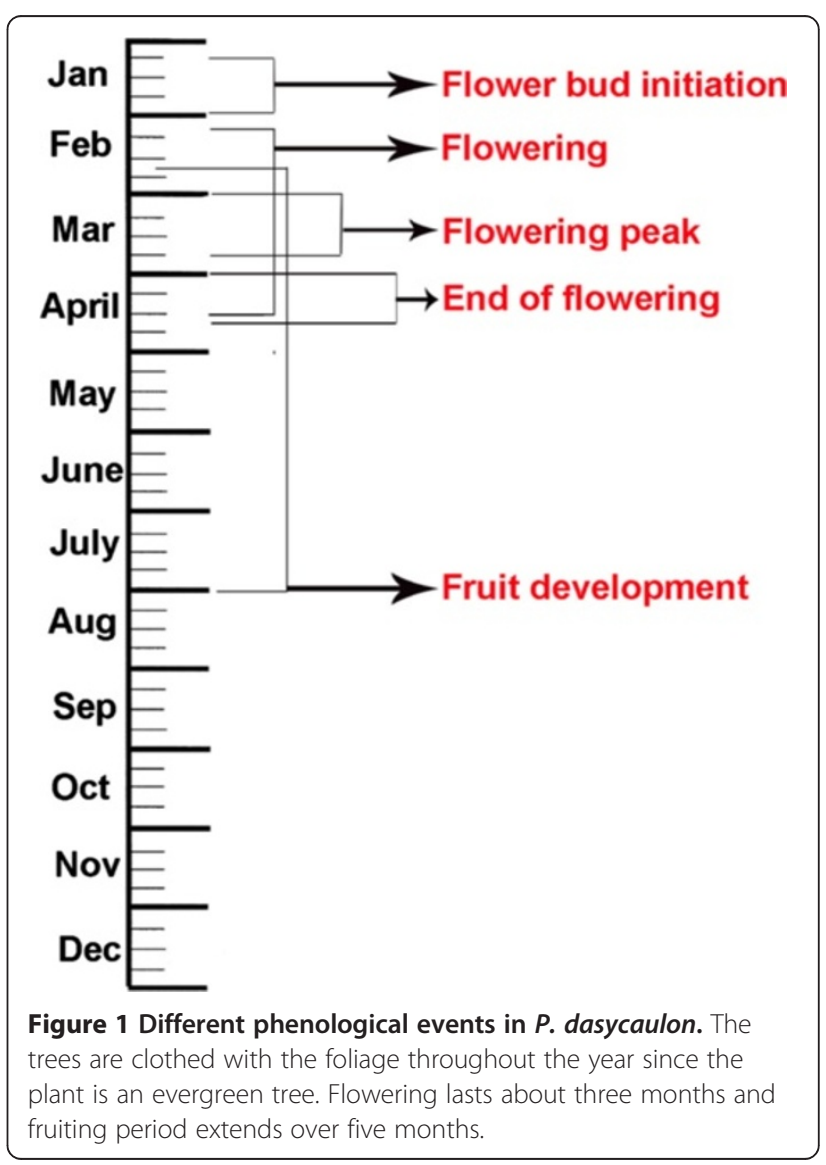


properly recorded. Some of the visitors were captured for identification.

\section{Results}

\section{Phenology}

Figure 1 presents the details of phenological events. In $P$. dasycaulon total loss of foliage was never observed as the plant is an evergreen tree. The plant was covered fully with green leaf throughout the year (Figure 2A). The average leaf amount was uniform throughout and there was no leaf shedding season. About one month before flowering new leaves sprouted from the tip of the buds. These new leaves appeared light green (Figure 2B) as compared to mature leaves which remained dark green. The flower buds started the development during the second week of January. Although the flowering started in February in most of the populations, some intermittent flowering occurred during January in some populations. But these flowers did not produce any fruits. Flowering started in February and continued till the third week of
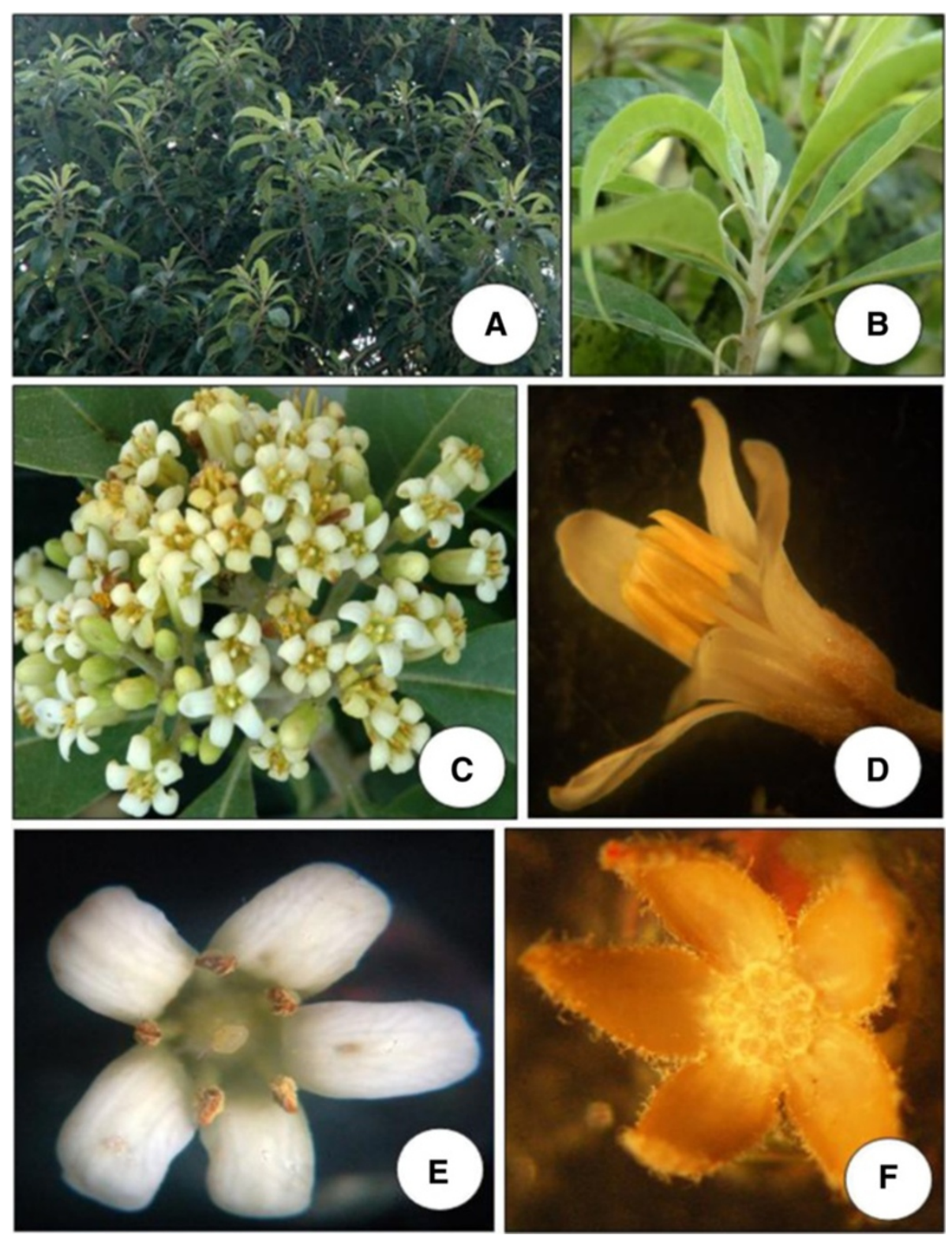

Figure 2 The plant and flower of $\boldsymbol{P}$. dasycaulon. A. A tree growing in the study site during the growth period. B. New flush developing before the onset of flowering from the apical regions of the plant. The colour of newly emerged leaf is light green. $\mathbf{C}$. An inflorescence during flowring peak. D. A single flower during anthesis. The anthers are not dehisced. E. A single flower 12 hour after anthesis. The anthers have dehisced. F. Calyx after removing all other floral parts. 
April (Figure 2C). Flowering peak was observed from the first week of March to fourth week of March. Flowering showed a decline from the first week of April and complete disappearance of flowers were found in the third week of April. In some plants the flowering continued up to the month of July. However, these flowers produced very less fruits (less than 2\%). Fruit development started early in the first formed flowers. Maximum flower to fruit ratio was observed during the peak flowering period (19\%). Fruit development took more time and average time required for flowering to fruit dehiscence took about 3 months. Some fruits were observed on the plant even during the month of August. Since the fruits were dehiscent, the mature fruits were dehisced and the seeds were dispersed automatically.

\section{Floral biology}

The floral traits of $P$. dasycaulon are presented in Table 1. Inflorescence is a terminal raceme (Figure 2C) and the total number of flowers per inflorescence ranged from 96-217. Each day an average number of $10 \pm 2$ flowers per inflorescence opened at the peak of the flowering period. Inflorescence had several small branches

Table 1 An overview of various floral traits such as type of inflorescence, flowering period, type of flower, colour of flower, odour of flower, presence of nector, flower opening time, anther dehiscence time, number of anthers per flower, average number of pollen grains per flower, average number of ovules per ovary, pollen-ovule ratio, type, shape, size and viability of pollen and stigma type of $P$. dasycaulon

\begin{tabular}{|c|c|}
\hline Parameters & Observations \\
\hline Inflorescence & Simple raceme \\
\hline Flowering period & February-April \\
\hline Flower & Hermaphrodite and zygomorphic \\
\hline Flower colour & Cream \\
\hline Odour & Mild fragarance \\
\hline Nectar & $\mathrm{Nil}$ \\
\hline Flower opening & 8:30-9:30 AM \\
\hline Anther dehiscence & Bursting inwards by slits \\
\hline Number of anthers/flower & 5 \\
\hline $\begin{array}{l}\text { Average number of } \\
\text { pollengrains/flower }\end{array}$ & 20800 \\
\hline Average number of ovules/ovary & $3-8$ \\
\hline Pollen-ovule ratio & 2600:01:00 \\
\hline Pollen type & Trizonocolpate \\
\hline Pollen shape & Triangular \\
\hline Pollen size & $45 \pm 5.6 \mu \mathrm{m}$ \\
\hline Pollen viability & $64 \pm 4 \%$ \\
\hline Stigma type & Capitate \\
\hline
\end{tabular}

and the flowers were arranged in an acropetal succession on it. Flowers were small, short pedicellate, complete, zygomorphic, bisexual, pentamerous, polypetalous, hypogynous and light cream in colour with an average length of $1.14 \mathrm{~cm}$ (Figure 2D and E). The flower had a pungent odour. Calyx consisted of five free sepals with an average length of $0.19 \mathrm{~cm}$ (Figure 2F). Corolla consisted of five whitish cream coloured petals with an average length of $0.78 \mathrm{~cm}$ (Figure 3B). It took about three weeks from flower bud initiation to flower anthesis (Figure 3A). Anthesis started at 08:30 AM and the flowers were completely opened by approximately 09:30 AM.

The androecium consisted of five stamens present in the form of a ring around the carpel and they were present at the same level of stigma (Figure 3C). Average length of stamen was $0.72 \mathrm{~cm}$ (filament $=0.23 \mathrm{~cm}$, and anther $=0.49 \mathrm{~cm}$; Table 2). Anthers were basifixed and yellowish while the filament was short and creamy in colour (Figure 3D). The yellowish anthers dehisced between 10:00-11:30 AM. Anther dehiscence took place through a longitudinal slit. Usually the anthers dehisced approximately 30 minutes after flower anthesis and shed $90 \%$ of the pollen within $2-3$ hours. The flowers that do not set fruits abscised within 3-4 days. The petals wilted and fell down and the stamens dried from the basal part of the ovary. The ovary remained attached to the pedicel after pollination but the apical portion of the pistle i.e. stigmatic portion, dried up.

Acetolysis of the pollen revealed the pollen morphology. The pollen grains were triangular and trizonocolpate with $45 \pm 5.6 \mu \mathrm{m}$ in size (Figure $4 \mathrm{~B}$ ). Pistil was white cream in colour and differentiated into stigma, style and ovary, having an average length of $0.78 \pm 0.4 \mathrm{~cm}$ at anthesis (stigma $=0.026 \pm 0.003 \mathrm{~cm}$, style $=0.35 \pm 0.02 \mathrm{~cm}$, ovary $=0.41 \pm 0.04 \mathrm{~cm}$; Figure $3 \mathrm{E}$ ). The stigma was wet, non-papillate and capitate. Stigma contained a thin film of exudates under the light microscope at the time of anthesis. Style presented medium size with average length of $0.35 \pm 0.02 \mathrm{~cm}$. Superior ovary was densely covered with papillate hairs and contained 3-8 ovules (Figure 3E).

\section{Pollen/ovule $(\mathrm{P} / \mathrm{O})$ ratio}

The pollen:ovule ratio $(\mathrm{P} / \mathrm{O})$ has traditionally been widely used as a rough estimator of breeding system studies. It has been shown that plant breeding systems are associated with particular floral traits. Pollen and ovule numbers per flower estimated in 2008 to 2011 were used to calculate the pollen:ovule ratio. Total pollen production per flower averaged 20800 and the number of ovules per flower varied between 3 to 8 . In the present investigation the pollen ovule ratio of $P$. dasycaulon was 2600:1 (Table 1). 

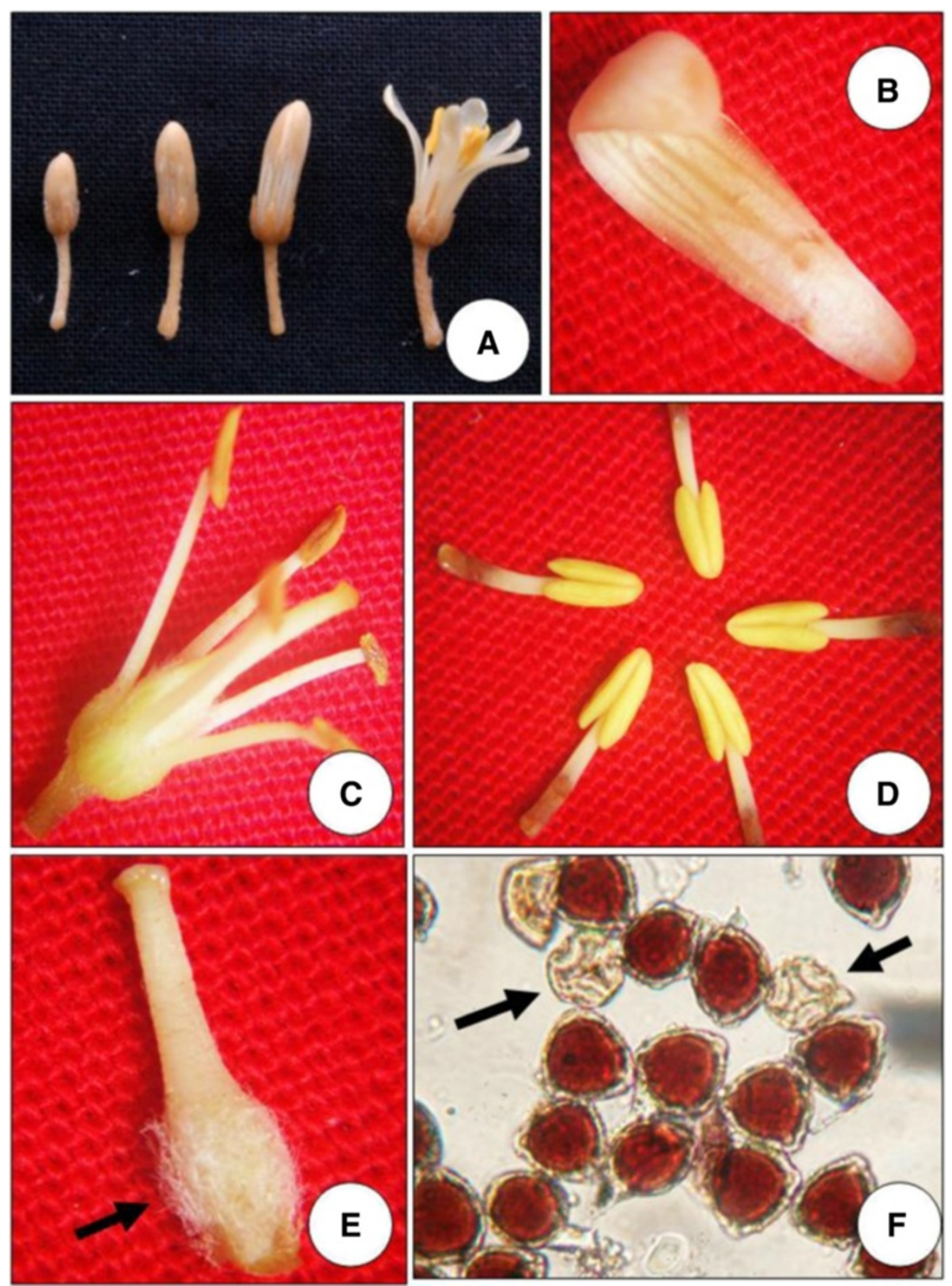

Figure 3 Characteristic of flower in P. dasycaulon. A. Flower bud at various stages of development. The last figure shows a flower at the time of anthesis. B. A single petal excised from the flower after anthesis. C. Figure showing stamens and pistil 4 hour after anthesis after removing all other floral parts. D. Anthers removed from a single flower at anthesis. E. An excised pistil showing stigma, style and ovary. Note luxurently growing papillate hairs at the basal region of the ovary. F. Pollen sterility assessed by acetocarmine staining. Arrows indicate the sterile pollens.

Table 2 Flower characteristics in $P$. dasycaulon

\begin{tabular}{lc}
\hline Parameters studied & Measurement* \\
\hline Flower length & $1.14 \pm 0.04 \mathrm{~cm}$ \\
Length of calyx & $0.19 \pm 0.03 \mathrm{~cm}$ \\
Length of corolla & $0.78 \pm 0.05 \mathrm{~cm}$ \\
Length of stamen & $0.72 \pm 0.04 \mathrm{~cm}$ \\
Length of pistil & $0.69 \pm 0.05 \mathrm{~cm}$ \\
\hline
\end{tabular}

*Average of 8 flowers from each plant.

\section{Reproductive biology}

Acetocarmine staining showed $66 \pm 6 \%$ fertile pollen at the time of anther dehiscence (Figure 3F). Studies with pollen germination in vitro revealed that the pollen grains viability was $64 \pm 4 \%$ at the time of anthesis (Table 1 ; Figure 4A). Pollen viability showed a steady decrease $4 \mathrm{~h}$ after storage in the laboratory $\left(25 \pm 2^{\circ} \mathrm{C}\right)$ conditions and viability reached less than $15 \pm 2 \% 12 \mathrm{~h}$ after storage in lab $\left(25 \pm 2^{\circ} \mathrm{C}\right)$ conditions. However, $46 \pm 3 \%$ of the 

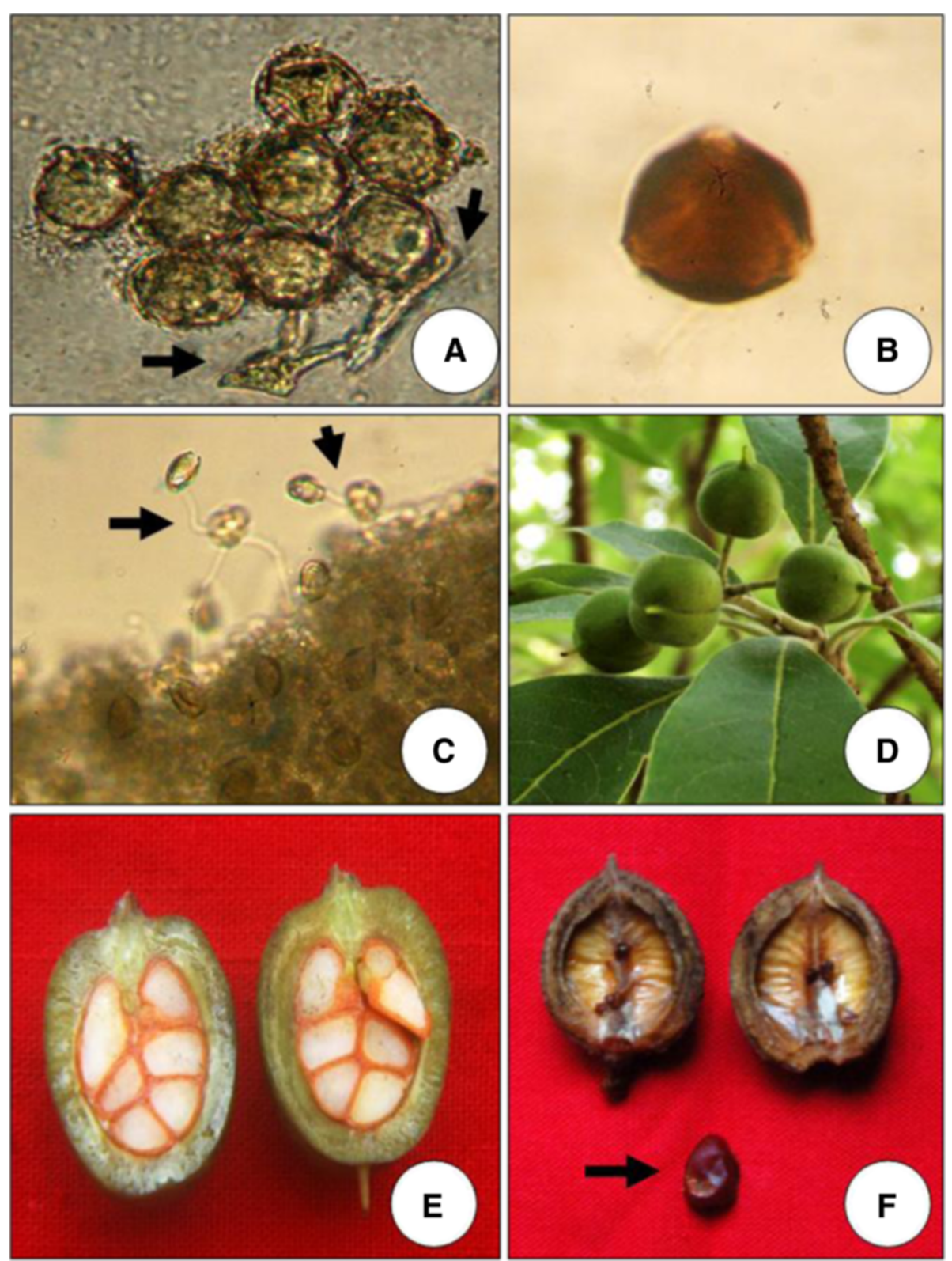

Figure 4 Pollen germination and fruit in P. dasycaulon. A. In vitro pollen germination. Arrows indicate the germinating pollen and pollen tube. B. A single pollen after acetolysis. Note the trizonocolpate nature of the pollen. C. Pollen germination on stigmatic surface observed under normal microscope after hydrolysing the pistil. D. Four mature fruits growing on a tree from study site. E. Longitudinal section of a single fruit showing 6 red seeds inside. F. A dehisced fruit with a single seed.

pollen grains stored at $4^{\circ} \mathrm{C}$ in a refrigerator remained viable after $24 \mathrm{~h}$ (Figure 5). The number of pollen grains in an anther was $5246 \pm 845$ (mean \pm SD) and per flower was $26230 \pm 1021$ (mean \pm SD).

\section{Fruit set}

Details of fruit set by various pollination experiments are presented in Table 3. Fruit set under open-pollination was poor and only $24 \%$ of the flowers set fruits with $58.3 \%$ fruits having seeds inside. None of the emasculated and bagged flowers as well as those bagged without emasculation sets fruits (Table 3). Therefore, it is confirmed that in this species there is no apomixy or autogamy. Additionally, none of the manually self pollinated flowers formed fruits, while over $57 \%$ of the cross pollinated flowers formed fruits.

The average flower and fruit production during the study period of 12 labelled individuals were presented in Table 4 . The average number of total flowers per plant varies in each year. Average number of total flowers per 


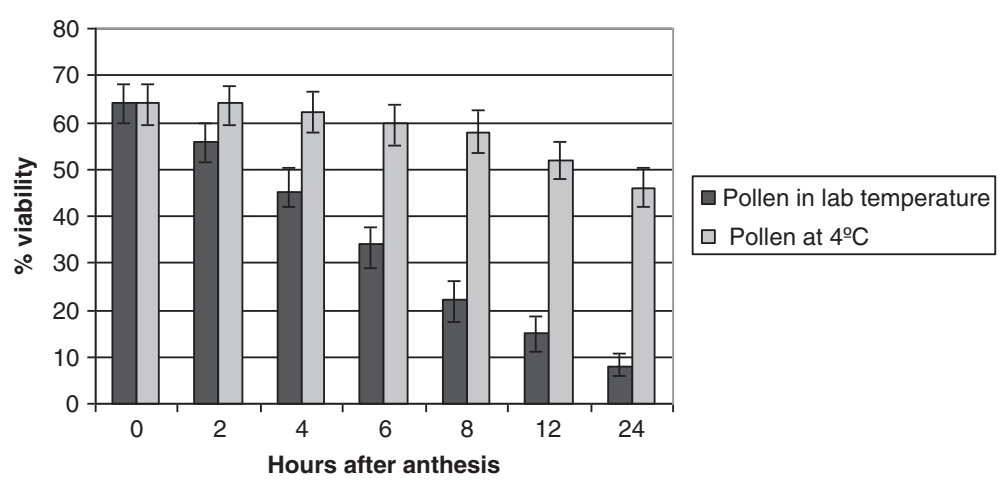

Figure 5 Viability of pollen stored at lab temperature and at $4^{\circ} \mathrm{C}$ in relation to time after flower anthesis (indicated as 0 ).

plant were 18102, 15438 and 23541 and ripening fruits per plant were 2302, 2234 and 2613 during the year 2009, 2010 and 2011 respectively (Table 4). However, the number of mature fruits per plant was 908, 838 and 1203 during the year 2009, 2010 and 2011 respectively. Fruit was a globose, glabrous capsule with 1.0 to $1.5 \mathrm{~cm}$ in diameter (Figure 4D). Mature seeds were dark brown in colour and covered with a resinous viscous fluid (Figure 4E). The ovoid capsule dehisced by 2 equal valves (Figure 4F). Number of seeds varied from 3-8. However, most of the seeds contained 3-4 seeds only. Seeds measured about $5.0 \mathrm{~mm}$ in diameter (Figure 4F).

\section{Floral visitors}

The flowers were visited by honey bees, Apis dorsata and Apis indica and butterflies. Honey bees and butterflies visited the flower in the morning after anthesis. All these visitors played significant role in cross-pollination.

An average number of floral visitors in 12 different plants studied during the peak flowering period were presented in Figure 6. The maximum floral visitors (12 honey bees and 2 butterflies) were recorded during 11:0012:00 AM. Based on our observations it can be realized that the effective pollinators are honey bees and butterflies. Cream colour and odour of flowers attracted the pollinators towards the flower after anthesis. Occasionally it

Table 3 Fruit and seed set in treated flowers

\begin{tabular}{llll}
\hline Treatment & $\begin{array}{l}\text { No of flowers } \\
\text { pollinated }\end{array}$ & $\begin{array}{l}\text { No. of fruits } \\
\text { developed (\%) }\end{array}$ & $\begin{array}{l}\text { No of fruits } \\
\text { having seeds (\%) }\end{array}$ \\
\hline $\begin{array}{l}\text { Bagged without } \\
\text { emasculation }\end{array}$ & 35 & 0.0 & - \\
$\begin{array}{l}\text { Bagged after } \\
\text { emasculation }\end{array}$ & 35 & 0.0 & - \\
$\begin{array}{l}\text { Self-pollination } \\
\text { Cross pollination }\end{array}$ & 35 & 0.0 & - \\
Natural pollination & 50 & $20 \pm 2.3(57)$ & $16 \pm 2.1(80)$ \\
\hline
\end{tabular}

Values indicate the average of three independent experiments done in 12 plants. was noticed that ants, house flies and spiders also visited the flowers during afternoon between 2:00 PM-4:00 PM. However, on the basis of visitation rates, transfer of pollen on virgin stigma and pollen load on body parts of insects, it was confirmed that honey bees and butterflies are the effective pollinators in this plant.

\section{Discussion}

The basic knowledge on reproductive biology is not only essential for evolutionary and systematic studies (Anderson 1995) but also important for effective conservation strategies (Holsinger 1991; Bernardello et al. 1999) for endemic and threatened plants with very few populations like $P$. dasycaulon. The most crucial stages in the life cycle of any plant include reproduction, dispersal of seeds, germination followed by seedling establishment (Kavanagh and Carleton 1990). Reaching the reproductive phase is an important step in the life cycle of a plant as far as resource allocation is concerned since the assimilates reserved previously for vegetative growth will be utilized for the generative purposes (Seifert and Muller-Starck 2009).

From our study we found that $P$. dasycaulon has an annual flowering pattern with a single major flowering episode which has been reported in some other species like Caesalpinia echinata (Borges et al. 2009). Fresh leaf flesh emergence prior to flowering observed in our system is a typical pattern observed in several tree species growing in various habitats (Bullock 1995). During the flowering to fruiting period there was slight asynchrony

Table 4 Average flower and fruit production per plant during the study period of 12 labelled individuals

\begin{tabular}{llll}
\hline Year & $\begin{array}{l}\text { Average number } \\
\text { of flowers/plant }\end{array}$ & $\begin{array}{l}\text { Average number of } \\
\text { ripening fruits/plant }\end{array}$ & $\begin{array}{l}\text { Average number of } \\
\text { mature fruits/plant }\end{array}$ \\
\hline 2009 & $18,102 \pm 1041$ & $2302 \pm 123$ & $908 \pm 32$ \\
2010 & $15,438 \pm 1062$ & $2234 \pm 76$ & $838 \pm 32$ \\
2011 & $23,541 \pm 1232$ & $2613 \pm 112$ & $1203 \pm 21$ \\
\hline
\end{tabular}




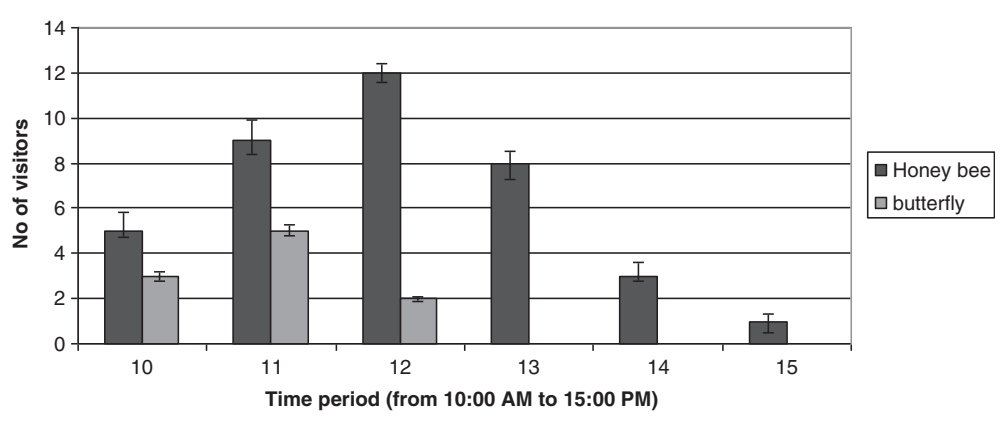

Figure 6 Average number of floral visitors in 12 different plants studied during the peak flowering period.

among the studied plants. Such asynchrony among individuals may be due to microhabitat differences as reported by Newstrom et al. (1994). Detailed information on phenological studies helps in the conservation as well as framing effective measures for successful cultivation of a species (Delanoe et al. 1996; Wafai et al. 1996).

$P$. dasycaulon is a self incompatible plant with comparatively low reproductive output. The predominant selfincompatibility nature of forest trees is directly related to selective pressure to maintain genetic variability (Bawa 1974). Variations especially genetic variation has long term evolutionary consequence and form the basis of the raw material for natural selection to operate and exploitation in the selection of superior genotypes at the hands of a breeder. Self-incompatibility is the most efficient method of controlling self pollination and thereby inbreeding in higher plants (Mandujano et al. 2010). Hand pollination resulted in more fruit set than natural pollination and this confirm that there is pollination deficit in this species and is mainly attributed to the lack of pollinators or lower effectiveness of the pollinators. In this species the main pollinators are honey bees and are known for less effective pollinators as compared to other bee species since they are more generalist and they collect pollen from various pollen resources resulting in the heterospecific pollen on the stigmatic surface (Westerkamp 1991). Habitat loss and excessive pesticide usage may be the reasons for low number of pollinators (Kearns and Inouye 1997). Forest destruction and fragmentation may often cause damage to diverse pollinators. Highly mobile species may be more resistant to habitat fragmentation than other species (Steffan and Tscharntke 1999; Tilman 1994).

Pollen viability test, percentage of pollen germination and pollen load on stigmatic surface gave a clear cut evidence that $P$. dasycaulon is a self-incompatible species under natural condition. Although the number of pollen grains are more, only very few are viable in $P$. dasycaulon. But viable pollen grains had done effective fertilization. Low temperature often influenced the pollen tube germination.
Pollen production in a plant depends upon several factors including season, anther length, pollen grain size and mode of anther dehiscence (Stanley and Linskens 1974). Recent studies showed that the effects of pollen quantity and quality on reproductive success have become an important issue in plant conservation (Dudash and Fenster 2000; Rocha and Aguilar 2001; Byers 2004; Colling et al. 2004) as they are closely related to demographic and genetic factors that affect population decline and extinction. In the present study, in vitro pollen germination studies showed moderate pollen viability (64\%). In vitro studies often provide lot of information on physiological and biochemical nature of pollen germination and pollen tube growth on stigmatic surface (Shivanna and Johri 1985).

The fruit set for all plants studied were low with low fruit to flower ratios. This may be due to changes in various climatic conditions including rainfall, temperature variations and humidity resulting in altered physiological condition of the plant. The failure of high rate of transformation from flower to fruit indicates that the fruit set in this plant is resource limited (Corbet 1998; Fleming and Holland 1998). The probable other reasons for reduced fruit set include reduced pollen viability, low pollen loads on stigmas, the absence of pollen tubes at the base of the style, small population size, space limitation, genetic load and climatic change which can cause low fruit set (Lamont et al. 1993; Hermanutz et al. 1998; Dorken and Eckert 2001). However, specific studies were not conducted to examine which factor/s are more important in determining low fruit set in $P$. dasycaulon. Low fruit production might indicate low efficiency of the pollination syndrome (Whelan and Goldingay 1989).

$P$. dasycaulon is a stable self-incompatible plant. This is evident from the pollination experiments as $57 \%$ of the cross pollinated flowers set fruits and seeds.

The low fruit set in natural pollinated flowers as compared to artificial cross pollinated flowers strongly suggest the requirement of some external agents necessary for effective pollination (Sreekala et al. 2008). Others are 
of the view that the low fruit:inflorescence ratio is related to the physiological incapacity of the mother plant to generate and ripe as many fruits as flowers (Koptur 1984; Ruiz and Arroyo 1978). Moreover the perennial trees must interact with the environmental conditions at all times of the year, and flowering and fruiting is closely related to seasonal climatic changes (Sedgley and Griffin 1989).

Pollination success basically relies on the availability of pollen and pollinator. All the $P$. dasycaulon plants investigated in this study exhibited high levels of pollinator dependence. The cream colored corolla and the floral scent attract the insects especially honey bees. It is reported that insects especially honey bees locate flowers by visual clues and to orient during landing by floral fragrance cues (Dobson et al. 1999; Keven 1983). Honey bees, and butterflies were observed during the entire flowering period and were effective pollinator as they collected pollen and transferred on the stigmatic surface.

\section{Conclusions}

A detailed account of various aspects of reproductive biology such as phenology, floral biology, pollen/ovule $(\mathrm{P} / \mathrm{O})$ ratio, breeding systems, floral visitors were investigated in the present study. The Flowers in $P$. dasycaulon is comparatively small, hermaphrodite, short pedicellate, complete, zygomorphic, pentamerous, polypetalous, hypogynous and light cream in colour. The flower anthesis started at $08.30 \mathrm{~h}$ and anther deshiscence at 10.00-11.30 h. The stigma is wet, non-papillate, capitate and contains a thin film of exudates. Our study revealed the presence of some floral visitors like bees and butterflies. From our study it is confirmed that the plant is self-incompatible and an out crosser. This detailed investigation on reproductive biology is important because, the evolutionary success and survival of this plant is largely determined by the efficacy of their reproductive performance.

\section{Competing interests}

The authors declare that they have no competing interests.

\section{Authors' contributions}

TDT designed research, analyzed data and corrected the manuscript. KKG conducted experiments and wrote the paper. Both authors read and approved the final manuscript.

\section{Authors' information}

TDT is the Assistant Professor and KKG is the project fellow in Department of Botany, St. Thomas College, Palai, Kottayam, Kerala, India.

\section{Acknowledgements}

TDT acknowledges the financial assistance from UGC, Government of India, in the form of a major research project (Project no. 38-233/2009). TDT acknowledges the financial support from Indian NationalScience Academy (INSA, New Delhi) and Polish Academy of Sciences (PAS), Poland.

Received: 20 June 2013 Accepted: 2 December 2013

Published: 2 February 2014

\section{References}

Adam P, Williams G (2001) Dioecy, self-compatibility and vegetative reproduction in Australian subtropical rainforest trees and shrubs. Cunninghamia 7:89-100 Anderson GJ (1995) Systematics and reproductive biology. In: Hoch PC, Stephenson AG (ed) Experimental and molecular approaches to plant systematics, Monogr Syst Bot 53. Missouri Botanical Garden, St. Louis, pp 263-272

Bawa KS (1974) Breeding systems of tree species of a lowland tropical community. Evolution 28:85-92

Bawa KS, Webb CJ (1984) Flower, fruit and seed abortion in tropical forest trees: implications for the evolution of paternal and maternal reproductive patterns. Am J Bot 71:736-751

Bernardello G, Anderson GJ, Lopez SP, Cleland MA, Stuessy TF, Crawford DJ (1999) Reproductive biology of Lactoris fernandeziana (Lactoridaceae). Am J Bot 86:829-840

Borges LA, Sobrinho MS, Lopes AV (2009) Phenology, pollination, and breeding system of the threatened tree Caesalpinia echinata Lam. (Fabaceae), and are view of studies on the reproductive biology in the genus. Flora 204:111-130

Brewbaker JL, Kwack BH (1963) The essential role of calcium ion in pollen germination and pollen tube growth. Amer J Bot 50:859-865

Byers DL (2004) Pollen quantity and quality as explanations for low seed set in small populations exemplified by Eupatorium (Asteraceae). Amer J Bot 82:1000-1006

Bullock SH (1985) Breeding systems in the flora of a tropical deciduous forest in Mexico. Biotropica 17:287-301

Bullock SH (1995) Plant reproduction in neotropical dry forest trees. In: Bullock SH, Mooney HA, Medina E (ed) Seasonally dry tropical forests. Cambridge Uni- versity Press, Cambridge, pp 277-296

Chou CH, Chen IS, Hwang TL, Wang TC, Lee TH, Cheng LY, Chang YC, Cho JY, Chen JJ (2008) Phthalides from Pittosporum illicioides var. Illicioides with inhibitory activity on superoxide generation and Elastase release by neutrophils. J Nat Prod 71:1692-1695

Colling G, Reckinger C, Matthies D (2004) Effects of pollen quantity and quality on reproduction and offspring vigour in the rare plant Scorzonera humilis (Asteraceae). Amer J Bot 91:1774-1782

Corbet SA (1998) Fruit and seed production in relation to pollination and resources in bluebell Hyacinthoides non-scripta. Oecologia 114:349-360

Cragg GM, Newman DJ, Yang SS (2006) Natural product extracts of plant and marine origin having antileukemia potential. J Nat Prod 69:488-498

Cruden RW (1977) Pollen-ovule ratio: a conservative indicator of breeding systems in flowering plants. Evolution 31:32-46

Delanoe O, Montmollin B, de Olivier L (1996) The IUCN/ SCC Mediterranean Islands Plant Specialist Group-Conservation of Mediterranean island plants. Strategy for action gland, 1st edition. Switzerland IUCN, Switzerland

Dobson HEM, Danielson EM, van Wesep ID (1999) Pollen odor chemicals as modulators of bumble bees foraging on Rosa rugosa Thunb (Rosaceae). PI Sp Biol 14:153-166

Dorken ME, Eckert CG (2001) Severely reduced sexual reproduction in northern populations of a clonal plant, Decodon verticillatus (Lythraceae). J Eco 89:339350

Dudash MR, Fenster CB (2000) Inbreeding and out breeding depression in fragmented populations. In: Young A, Clarke G (ed) Genetics, demography and viability of fragmented populations. Cambridge University Press, Cambridge, United Kingdom, pp 35-53

Feng C, Li BG, Gao XP, Qi HY, Zhang GL (2010) A new triterpene and an antiarrhythmic liriodendrin from Pittosporum brevicalyx. Arch Pharm Res 33:1927-1932

Fleming TH, Holland JN (1998) The evolution of obligate pollination mutualisms: Senita cactus and Senita moth. Oecologia 114:368-375

Fournier LA (1974) Un metodo cuantitativo para la medicion de caracteristicas fenologicas en arboles. Turrialba 24:422-423

Hermanutz L, Innes D, Denham A, Whelan R (1998) Very low fruit:flower ratios in Grevillea (Proteaceae) are independent of breeding system. Aust J Bot 46:465-478

Holsinger K (1991) Conservativity of genetic diversity in rare and endangered plants. In: Dudley EC (ed) The unity of evolutionary biology. The proceedings of the fourth International Congress of systematic and evolutionary biology. Dioscorides Press, Portland, pp 626-633

Kavanagh K, Carleton TJ (1990) Seed production and dispersal patterns in populations of. Liriodendron tulipifera at the northern edge of its range in southern Ontario, Canada. Can J Forest Res 20:1461-1470 
Kearns CA, Inouye DW (1993) Techniques for pollination biology. University Press of Colorado Niwot, Colorado

Kearns CA, Inouye DW (1997) Pollinators, flowering plants and conservation biology. Bio Sci 47:297-307

Keven PG (1983) Floral colours through the insect eye: what they are and what they mean. In: Jones CE, Little RJ (ed) Handbook of experimental pollination biology. Van Nostrand Reinhold, New York, pp 3-30

Koptur S (1984) Out crossing and pollinator limitation of fruit set: breeding systems of neotropical Inga. Evolution 38:1130-1143

Lamont BB, Klinkhamer PGL, Witkowski ETF (1993) Population fragmentation may reduce fertility to zero in Banksia goodie -a demonstration of the Allee effect. Oecol 94:446-450

Mandujano MC, Carrillo-Angeles I, Martınez-Peralta C, Golubov J (2010) Reproductive biology of Cactaceae. In: Ramawat KG (ed) Desert plants. Springer-Verlag, Berlin Heidelberg, pp 197-230

Maoka T, Akimoto N, Kuroda Y, Hashimoto K, Fujiwara Y (2008) Pittosporumxanthins, Cycloaddition products of Carotenoids with a-Tocopherol from seeds of Pittosporum tobira. J Nat Prod 71:622-627

Maynard SJ (1978) The evolution of sex. Cambridge University Press, Cambridge

McKone MJ, Webb CJ (1988) A difference in pollen size between the male and hermaphrodite flower of two species of Apiaceae. Aust J Bot 36:331-337

Moza MK, Bhatnagar AK (2007) Plant reproductive biology studies crucial for conservation. Curr Sci 92:1207

Mullett TL (1996) Ecological aspects of sweet Pittosporum (Pittosporum indulatum Vent): Implections for control and Management. In: Shepherd RCH (ed) 11th Australian Weeds Conference proceedings: where in the world is weed science going? pp 489-492

Newstrom LE, Frankie GW, Baker HG (1994) A new classification for plant phenology based in flowering patterns in lowland tropical rain forest trees at La Selva, Costa Rica. Biotropica 26:141-159

Primack RB (1993) Vulnerability to extinction. Essentials of conservation biology. Sinnauer Associates Inc, Sunderland, USA

Radford AE, Dickinson WC, Massey JR, Bell CR (1974) Vascular plant systematics. Harper and Row Publishers, New York

Rocha OJ, Aguilar G (2001) Reproductive biology of the dry forest tree Enterolobium cyclocarpum (Guanacaste) in Costa Rica: a comparison between trees left in pastures and in continuous forest. Amer J Bot 88:1607-1614

Rosakutty PJ, Roslin AS, Ignacimuthu S (2010) Anti-inflammatory and acute toxicity effects of Pittosporum tetraspermum wight and Arn. on rats. J Geophys Res 2:14-20

Ruiz T, Arroyo KMT (1978) Plant reproductive ecology of a secondary deciduous tropical forest in Venezuela. Biotropica 10:221-230

Sedgley M, Griffin AR (1989) Sexual reproduction of tree crops. Academic Press, London

Seifert T, Muller-Starck G (2009) Impacts of fructification on biomass production and correlated genetic effects in Norway spruce (Picea abies [L.] Karst.). Eur J For Res 128:155-169

Seo Y, Berger JM, Hoch J, Neddermann KM, Bursuker I, Mamber SW, Kingston DGl (2002) A New Triterpene Saponin from Pittosporum viridiflorum from the Madagascar rainforest. J Nat Prod 65:65-68

Shivanna KR, Johri BM (1985) The Angiosperm Pollen structure and function. Wiley Eastern Ltd Publisher, New Delhi

Shivanna KR, Rangaswamy NS (1993) Pollen biology a laboratory manual. Narosa publishing house, New Delhi, India, p 87

Steffan DI, Tscharntke T (1999) Effect of habitat isolation on pollinator communities and seed set. Oecol 121:432-440

Stanley RG, Linskens HF (1974) Pollen: biology biochemistry and management. Springer, Berlin

Sreekala AK, Pandurangan AG, Ramasubbu R, Kulloli SK (2008) Reproductive biology of impatiens coelotropis Fischer, a critically endangered balsam from the Southern Western Ghats. Curr Sci 95:386-388

Sutherland S (1986) Floral sex ratios, fruit set, and resource allocation in plants. Ecology 67:991-1001

Tilman D (1994) Competition and biodiversity in specially structured habitats. Ecology 75:2-16

Udayan PS, George S, Tushar KV, Balachandran I (2007) Ethnomedicine of Malapandaram tribes of Achenkovil forest of Kollam district, Kerala. Ind J Tradi Know 6:569-573

Wafai BA, Siddique MAA, Beigh Showket Y, Dar NA (1996) Reproductive biology of Patris (Aconitum heterophyllum Wall. ex. Royle; Ranunculaceae) an important rare and threatened Himalayan Drug plant. HUF-IUFRO Int
Workshop on Prospects of Medicinal Plants, Parmer YS University of Agricultural Sciences, Solan, H. P. India

Westerkamp C (1991) Honey bees are poor pollinators - Why? Plant Sys Evol 177:71-75

Whelan RJ, Goldingay RL (1989) Factors affecting fruit-set in Telopea speciosissima (Proteaceae): the importance of pollen limitation. J Ecol 77:1123-1134

Yesohdharan K, Sujana KA (2007) Ethnomedicinal knowledge among Malamalasar tribe of Parambikulam wild life sanctuary, Kerala. Ind J Tradi Know 6:481-485

doi:10.1186/1999-3110-55-15

Cite this article as: Gopalakrishnan and Thomas: Reproductive biology of Pittosporum dasycaulon Miq., (Family Pittosporaceae) a rare medicinal tree endemic to Western Ghats. Botanical Studies 2014 55:15.

\section{Submit your manuscript to a SpringerOpen ${ }^{\odot}$ journal and benefit from:}

- Convenient online submission

- Rigorous peer review

- Immediate publication on acceptance

- Open access: articles freely available online

- High visibility within the field

- Retaining the copyright to your article

Submit your next manuscript at $>$ springeropen.com 